\title{
Factors influencing work functioning after cancer diagnosis: a focus group study with cancer survivors and occupational health professionals
}

\author{
H. F. Dorland ${ }^{1}$ - F. I. Abma ${ }^{1}$ - C. A. M. Roelen ${ }^{1}$. \\ J. G. Smink ${ }^{2}$ - A. V. Ranchor ${ }^{2}$ U. Bültmann ${ }^{1}$
}

Received: 19 December 2014 / Accepted: 30 April 2015 /Published online: 29 May 2015

(C) The Author(s) 2015. This article is published with open access at Springerlink.com

\begin{abstract}
Purpose Cancer survivors (CSs) frequently return to work, but little is known about work functioning after return to work (RTW). We aimed to identify barriers and facilitators of work functioning among CSs.

Methods Three focus groups were conducted with CSs $(n=6$, $n=8$ and $n=8$ ) and one focus group with occupational health professionals $(n=7)$. Concepts were identified by thematic analysis, using the Cancer and Work model as theoretical framework to structure the results.

Results Long-lasting symptoms (e.g. fatigue), poor adaptation, high work ethics, negative attitude to work, ambiguous communication, lack of support and changes in the work environment were mentioned as barriers of work functioning. In contrast, staying at work during treatment, open dialogue, high social support, appropriate work accommodations and high work autonomy facilitated work functioning.

Conclusions Not only cancer-related symptoms affect work functioning of CSs after RTW but also psychosocial and work-related factors. The barriers and facilitators of work functioning should be further investigated in studies with a longitudinal design to examine work functioning over time.
\end{abstract}

Keywords Cancer · Qualitative research · Work functioning · Supportive care $\cdot$ Occupational rehabilitation

H. F. Dorland

h.f.dorland@umcg.nl

1 Department of Health Sciences, Community and Occupational Medicine, University of Groningen, University Medical Center Groningen, Groningen, The Netherlands

2 Department of Health Psychology, University of Groningen, University Medical Center Groningen, Groningen, The Netherlands

\section{Introduction}

Cancer survival rates have increased, due to earlier diagnosis and improved treatment $[1,2]$. At the time of diagnosis, half of all cancer patients are employed or available for employment $[3,4]$. A recent review showed that $64 \%$ of cancer survivors (CSs) returned to work within 6 months after diagnosis [5]. CSs try to get back to work to re-establish their former structure of everyday life as a normal and healthy existence [6]. It is known that work has both psychological benefits (e.g. identity, normalcy and fairness) [7] and practical benefits (e.g. income and social support) [8]. To date, many studies have focused on return to work (RTW) after cancer [9-11], but little is known about work functioning of CSs after RTW.

Work functioning captures the interplay between health status and performance (e.g. work scheduling demands, flexibility demands) and can be viewed as a continuum varying from working without any problems to not working at all [12, 13]. Work functioning refers to how CSs perform work tasks and goes beyond RTW in terms of the simple dichotomy of whether or not having resumed work [14]. Work functioning differs from related but more general constructs such as work ability and work engagement, because it focusses on the ability to meet specific work demands, expressed in percentage of time. Earlier studies showed that CSs experience health complaints for years after primary treatment, which may affect CSs functioning [15, 16], also at work [17]. To date, only a few studies have investigated CSs work functioning. For example, brain CSs were less productive than a control group without a life-threatening illness or chronic disease due to depressive symptoms, fatigue, cognitive limitations, insufficient sleep and negative problem solving orientation [18]. Breast CSs with fatigue or hot flashes reported work productivity below the healthy worker norm [19] and lower work productivity than their peers who never had cancer [20]. To 
date, research on work functioning is limited to cancer-related symptoms and little is known about other factors influencing CSs work functioning.

Many factors can affect work functioning of CSs. Feuerstein et al. [21] introduced the Cancer and Work model, a conceptual framework including health and well-being, symptoms, function, work demands and work environment of CSs as well as policies, procedures and economic factors. This theoretical model is valuable for identifying factors that affect work functioning, but it is important to get insight on barriers and facilitators of work functioning from different perspectives (e.g. CSs, occupational physicians, labour experts). The objective of this study was to explore barriers and facilitators of work functioning from the perspectives of CSs and occupational health professionals (OHPs).

\section{Methods}

This qualitative study used focus groups to explore authentic themes, independent of prevailing constructs or questionnaires.

\section{Inclusion criteria and recruitment}

Inclusion criteria for the CSs were RTW in the past 3 years, currently working ( $\geq 12 \mathrm{~h} / \mathrm{week}$ ) and able to communicate in Dutch. There was no restriction on cancer types. OHPs had to have experience in guiding CSs back to work. The absence of exclusion criteria ensured a diversity of experiences to provide a comprehensive insight into CSs' work functioning. CSs were recruited via occupational physicians and by contacting patient forums. OHPs were recruited from our professional network. CSs and OHPs interested to participate in a focus group received a letter from the research team with additional information about the study. Based on the information, CSs and OHPs decided to participate in the focus groups. Recruitment of participants stopped when a minimum of six and a maximum of nine persons per focus group agreed to participate.

\section{Focus group method}

Four focus groups were conducted: three with CSs and one with OHPs. Each focus group met once. The focus group discussions lasted up to $2 \mathrm{~h}$ and were led by an experienced moderator. Semi-structured interview schedules were used, facilitating wide-ranged explorations of the participants' thoughts and experiences [22]. The key question in all focus groups was as follows: Which factors hinder or facilitate the performance at work? Cues were the disease itself and its treatment, psychological and social aspects or work-related aspects.

Before the focus groups started, participants gave informed consent and completed a brief questionnaire about sociodemographics (i.e. age, gender, education level). CSs received additional questions about their cancer diagnosis and work situation (i.e. RTW date, job type, working hours per week). All procedures were reviewed and approved by the Medical Ethical Committee of the University Medical Center Groningen (M12.125242).

\section{Data analysis}

The discussions were audiotaped and transcribed verbatim by a professional transcriber. Sandelowski's qualitative description method was used for data analysis [23]. First, key topics were identified by listening to the taped discussions. Next, each transcript was thematically analysed using the key topics, to find the concepts that arose in the group discussions. Each transcript was coded by two independent reviewers. The codes were compared, contrasted, refined and grouped. During this process, researchers stayed close to the original transcripts to ensure that the themes reflected the actual data, not the researchers' interpretations [24]. All codes and themes were discussed until consensus was reached. To obtain a comprehensive picture of the relevant factors affecting work functioning, both CSs' and OHPs' perspectives were taken together. The Cancer and Work model [21] was used as theoretical framework to structure themes. Quotes from participant were used to illustrate the themes.

\section{Results}

\section{Sample characteristics}

Twenty-two CSs (7 men and 15 women) with a mean age of 47.2 years $(\mathrm{SD}=7.4)$ participated in the focus groups. CSs had various cancer diagnoses; the majority of them had breast cancer $(n=10)$. Most CSs $(68 \%)$ were highly educated (i.e. higher professional education, college or university) and $32 \%$ were medium educated (i.e. senior secondary vocational education, junior or senior general secondary education). The mean time since diagnosis was 1.8 years (range 0.4-4.8). CSs were back at work for an average of 15.0 months (range 1.4-43.1) and worked $25.3 \mathrm{~h} /$ week (range 12-40), predominantly in non-manual jobs, e.g. manager, analyst, coach or social worker. Seven OHPs (three men and four women) with a mean age of 51.5 years $(\mathrm{SD}=9.5)$ participated in one focus group: two labour experts, two insurance physicians, a nurse practitioner, an occupational physician and an occupational social worker. 


\section{Barriers and facilitators of work functioning}

\section{Health and well-being}

The long-lasting impact of cancer on work was mentioned as a barrier of work functioning, according to both CSs and OHPs. For example, fatigue often persists when CSs are back at work and hinders work functioning during the working day. Moreover, the majority of CSs said they realised the impact of having been diagnosed with cancer when they returned to work, which distracted them from work after RTW.

'When I went back to work I actually started to realise, so much happened... pff, excuse me.' [emotionally] CS 21

Due to the improvements in medical treatment and a changing societal view on cancer, RTW during treatment has become more common. Some CSs experienced that ongoing treatment negatively affected work (e.g. hormone supplementation may lead to emotional instability), while others mentioned that work helped them to feel less sick.

'I would prefer that people come to work when they have a good day, even if they have radiation therapy or chemotherapy. Often I hear employers say: as long as he is on those treatments, don't bother him. With all the good intentions, but I doubt if that is the right way forward.' OHP 6

'Continuing work helped me very much to stay in the normal process. Because then you don't feel so ill.' CS 13

The visibility of disease was mentioned by CSs as a barrier of work functioning. CSs experienced feelings of shame about bodily changes. Alternatively, invisible changes (e.g. fatigue, cognitive problems, adaptation) caused supervisors and colleagues to overestimate CSs' capacities.

'Colleagues are very kind, but at one point, I heard some of them saying: 'well, you're still here.' They mean: you look good, nothing is wrong with you anymore.' CS 22

\section{Symptoms}

Fatigue and cognitive problems were mentioned as barriers by most CSs. Both CSs and OHPs indicated that mental and physical fatigue led to concentration problems and making mistakes. CSs reported that fatigue was a reason for reducing working hours after RTW. Fatigue remained a barrier of work functioning in CSs who had been working for a longer period. Cognitive problems (e.g. problems with memory and multitasking) were also mentioned by CSs and OHPs as barriers of work functioning. One CS specified that concentration problems attenuated by reducing the amount of tasks on a working day.

'I have no problems with concentration. This has perhaps to do with the fact that I can indicate what I can handle (at work).' CS 4

\section{Function and work demands}

CSs experienced that disclosure to their supervisor and talking about expectations towards work facilitated work functioning. Ambiguous communication allowed divergent expectations and erroneous interpretations, which was mentioned as barrier of work functioning.

'My work has been accommodated but not at my own request. I have the feeling that colleagues see me as less worthy. I get reduced tasks, which causes stress and fatigue followed by poor concentration.' CS 6

Both CSs and OHPs stated that well-discussed accommodations of work tasks and work pace facilitated work functioning. Accommodating work in dialogue with the supervisor gave CSs the opportunity to express what accommodations would be most beneficial for their work functioning. Some CSs mentioned that the amount of work was reduced while other CSs were assigned alternative tasks. Possibilities for accommodations depend on the job and the relationship between supervisor and CS. Some OHPs reported that work accommodations were easier to arrange in smaller companies, while other OHPs thought that large companies had more possibilities to accommodate work.

\section{Work environment}

When back at work, most CSs experienced social support from the supervisor and colleagues in terms of interest, understanding, sharing of tasks and latitude in work. Some CSs indicated that the social support decreased over time. Although some CSs doubted the importance of workplace social support, lack of support at the workplace was mentioned by both CSs and OHPs as barrier of work functioning. Lack of attention and mutual understanding can lead to difficulties in collaborating with colleagues. In addition, some CSs said that the relationship with colleagues had changed because of disease experiences and changed work perceptions. CSs mentioned that they redefined the meaning of work after being 
diagnosed with cancer and that work (sometimes only temporarily) had become less of a priority in life. Some CSs mentioned that they were less concerned about the future and that they were less ambitious; career perspectives and promotion did not matter so much anymore.

'My colleagues have good intentions, but if you continue to work just like I did, no one will notice that you're sick. So, you can't blame them.' CS 13

'I am sorry that everyone is busy with other things, while I'm still busy with so many very serious things.' CS 2

Some CSs mentioned that they kept their colleagues informed about their disease by email or by visiting the workplace. Others did not want to disclose their disease to colleagues. Some CSs experienced that colleagues were reserved to talk about cancer and thought that an open dialogue might overcome this. CSs experienced negative ideas of colleagues about cancer and gossip as barriers of work functioning.

'The rumour was that I was not willing to go back to work. My bad luck was that some colleagues also had cancer and were able to return to work early. I could not return that fast. I felt that there was gossip about it and heard that from others. That really hurt my feelings.' CS 20

According to CSs and OHPs, the relationship with the supervisor was either a barrier or facilitator of work functioning. CSs mentioned that empathy and understanding were supervisor characteristics that could facilitate work functioning. Honest supervisors who try to understand CSs, put no pressure on work attendance and keep a considerate eye on CSs were seen as facilitators of work functioning. Alternatively, task-oriented, autocratic supervisors who ignored CSs were interested in productivity or pressured work attendance and hindered work functioning. OHPs mentioned that confident supervisors who provided opportunities and solutions facilitated work functioning, while a laissez-faire approach towards RTW and work attendance pressure hinder work functioning.

Changes in the organisation and management during absence from work were mentioned as barriers of work functioning. CSs were not familiar with new workplaces and new work procedures gave CSs the feeling that they had to prove themselves. In contrast, a stable work environment and working with familiar colleagues facilitated work functioning.

'The organization has changed over the past year. We work with flexible workspaces, which means that you cannot work on your familiar desk anymore. You have to wait and see in the morning where you end up. Sometimes you have to work next to people you have no connection with. In my experience this is rather difficult.' CS 5

According to some CSs, occupational physicians can negatively influence CSs work functioning when they fail to assert the interests of CSs, do not take CSs seriously and provide advice based on protocols rather than on CSs capacities. In contrast, occupational physicians could facilitate work functioning by listening to CSs, showing understanding and giving tailored advise about gradual RTW without pressuring work attendance.

'I have an occupational physician who stands between me and my employer. She looks after my interests, determines what is good for me, not for my employer.' CS 11

\section{CSs characteristics}

CSs and OHPs mentioned that inadequate coping with cancer hindered work functioning. Some CSs felt guilty and others were unsure because they could not perform all their tasks as they did before they were diagnosed with cancer. Consequently, CSs set themselves too high standards, based on their own expectations. The combination of high work ethics and fulfilling high expectations may lead to overstrain. Some OHPs mentioned that CSs immerse themselves in work to avoid the confrontation with cancer.

'People feel guilty. Surely there is understanding at the time that a colleague drops out due to cancer. But sometimes, colleagues have to do the additional work. Colleagues do understand that, but they are incredibly busy with that work, so that also gives a...., I wouldn't call it tension, but it is also something undescribed that you are not supposed to talk about.' OHP 7

'CSs handle their condition differently. Some people start working way too hard. They are determined to prove that they are healthy, but eventually relapse in sickness absence.' OHP 3

OHPs viewed a negative attitude towards work as barrier of work functioning, while a positive attitude was seen as facilitator of work functioning.

'Especially CSs with little affinity with their work report that they don't feel the need to work any more.' OHP 2

Some CSs mentioned their private situation as barrier of work functioning, for example when family or friends were concerned and advised against RTW. Alternatively, family support and a strong social network facilitated work 
functioning when family and friends encouraged the CS to go back to work or to stay at work.

\section{Discussion}

This focus group study provided new insight in barriers and facilitators of work functioning after cancer diagnosis from the perspectives of cancer survivors (CSs) and occupational health professionals (OHPs). Cancer-related symptoms, psychosocial factors, lack of support, ambiguous communication and poor working environment were mentioned as barriers of work functioning. In contrast, high (workplace and private) social support, an honest dialogue, appropriate work accommodations and high work autonomy facilitated work functioning.

Cancer has long-lasting adverse effects on work functioning. Fatigue and cognitive problems have shown to be present for a long time after cancer diagnosis and treatment [25-28]. In line with earlier studies [18-20], both CSs and OHPs mentioned that fatigue and cognitive problems affected work functioning. In addition, adaptation to the new situation after cancer diagnosis takes time. Most CSs experienced RTW as a new start and realised the physical and emotional burden of having been diagnosed with and treated for cancer when returning to work. Previously, Grunfeld et al. [28] reported that CSs needed an adaptation period when back at work and the demands of their role. Fatigue, poor concentration and the emotional confrontation with having had cancer impeded the adaptation process to being back at work. In our study, CSs mentioned that family and friends facilitated adaptation by encouraging them to stay at work. Alternatively, family and friends can hinder work functioning after RTW by expressing concerns about being at work.

OHPs mentioned that the societal view on cancer has changed and that cancer is more and more considered a chronic condition instead of a 'death sentence'. Nowadays, OHPs encourage CSs to think about staying at work during treatment. OHPs were very clear about the importance of staying involved in work, because prolonged absence from work may set up a threshold for RTW. Knott et al. [9] found that CSs who have been out of work for a long time lost self-confidence in how to cope with colleagues. The Dutch Guideline Cancer and Work [29] recommends OHPs to encourage CSs to continue working throughout cancer treatment. In the present study, some CSs mentioned that continuing work during treatment gave them a sense of 'normal life' and distracted them from worrying about cancer. Earlier research showed that CSs disliked the social isolation of being off work and valued the social contact they experienced at work [28]. CSs thought that an empathic supervisor, who motivates CSs to visit the workplace (e.g. for a coffee break), may facilitate work functioning. In our study, not all CSs agreed on the importance of social support at the workplace. Some CSs indicated that social support did not affect work functioning. Furthermore, CSs mentioned that social support wore off over time [30].

CSs experienced communication with the supervisor about mutual expectations towards work as important. Disease disclosure reduced ambiguity, helped to tailor work accommodations to the specific needs of CSs and provided a pleasant work climate. A 'safe' and open situation for dialogue is an important prerequisite for disease disclosure [30]. CSs who did not want to share information about their disease and treatment with supervisors and colleagues experienced difficulties due to unrealistic expectations towards work. McKay et al. [31] found that not disclosing any information to colleagues could also lead to uncertainty and resentment in CSs. OHPs mentioned that the attitude of CSs towards work and their coping with cancer were important for work functioning. Earlier, Abma et al. [30] stated that the way workers cope with chronic health problems was more important for work functioning than the medical diagnosis. De Boer et al. [32] reported that self-assessed ability to cope with work was a strong predictor of RTW among CSs, but the relationship with work functioning after RTW was not examined.

All focus groups were led by the same experienced moderator who ensured the quality of the group discussions, which was an asset of this focus group study. The participation of different stakeholders, the variety of cancer diagnoses and the semi-structured discussions provided a comprehensive picture of work functioning after RTW, although employers were not involved in the focus groups. A limitation of the focus group study is that the majority of the CSs were highly educated. Therefore, the result might be difficult to generalise to workers with a low educational level.

This qualitative study has several potential implications. Supervisors and OHPs have to be aware of the long-term effects of cancer and cancer treatment. Furthermore, they have to realise that CSs become aware of the physical and emotional burden of cancer when they resume work. Understanding and compassion from supervisor and OHPs can help CSs to familiarise with being back at work. Supervisors and OHPs have to tailor their guidance to the specific needs of the CS and have to motivate CSs to visit work during or after treatment. Disease disclosure and an open and honest dialogue increase mutual understanding and are necessary to facilitate appropriate work accommodations. These aspects can improve work functioning after RTW. In addition, supervisors, OHPs and colleagues should be aware of the importance of continued social support and their role in creating a safe and familiar work environment. Further research is needed to investigate the relative importance of the barriers and facilitators of staying at work and to examine work functioning of CSs after RTW over time. 
Acknowledgments This research project was funded by the Dutch Cancer Society (RUG 2011-5266). The funding institute had no role in the design, collection, analysis, and interpretation of data; in the writing of the manuscript and in the decision to submit the manuscript for publication.

\section{Compliance with ethical standards}

Conflict of interest The authors declare that they have no competing interest.

Ethical approval All procedures performed in studies involving human participants were in accordance with the ethical standards of the institutional and/or national research committee and with the 1964 Helsinki Declaration and its later amendments or comparable ethical standards. All procedures were reviewed and approved by the Medical Ethical Board Committee of the University Medical Center Groningen (M12.125242).

Informed consent Informed consent was obtained from all individual participants included in the study.

Open Access This article is distributed under the terms of the Creative Commons Attribution-NonCommercial 4.0 International License (http:// creativecommons.org/licenses/by-nc/4.0/), which permits any noncommercial use, distribution, and reproduction in any medium, provided you give appropriate credit to the original author(s) and the source, provide a link to the Creative Commons license, and indicate if changes were made.

\section{References}

1. Grunfeld EA, Rixon L, Eaton E, Cooper AF (2008) The organisational perspective on the return to work of employees following treatment for cancer. J Occup Rehabil 18:381-388

2. Verdecchia A, Guzzinati S, Francisci S, De Angelis R, Bray F, Allemani C, Tavilla A, Santaquilani M, Sant M (2009) Survival trends in European cancer patients diagnosed from 1988 to 1999. Eur J Cancer 45:1042-1066

3. Boer A (2014) The European Cancer and Work Network: CANWON. J Occup Rehabil 24:393-398

4. Verdonck-de Leeuw IM, van Bleek W, Leemans CR, de Bree R (2010) Employment and return to work in head and neck cancer survivors. Oral Oncol 46:56-60

5. Mehnert A (2011) Employment and work-related issues in cancer survivors. Crit Rev Oncol 77:109-130

6. Rasmussen DM, Elverdam B (2008) The meaning of work and working life after cancer: an interview study. Psycho-Oncol 17: $1232-1238$

7. Peteet JR (2000) Cancer and the meaning of work. Gen Hosp Psychiatry 22:200-205

8. Hoffman B (2005) Cancer survivors at work: a generation of progress. CA Cancer J Clin 55:271-280

9. Knott V, Zrim S, Shanahan E, Anastassiadis P, Lawn S, Kichenadasse G, Sukumaran S, Karapetis C, Koczwara B (2014) Returning to work following curative chemotherapy: a qualitative study of return to work barriers and preferences for intervention. 22:3263-3273

10. Mehnert A, Koch U (2013) Predictors of employment among cancer survivors after medical rehabilitation - a prospective study. Scand J Work Environ Health 39:76-87
11. Spelten ER, Sprangers MAG (2002) Factors reported to influence the return to work of cancer survivors: a literature review. PsychoOncol 11:124-131

12. Amick BC, Lerner D, Rogers WH, Rooney T, Katz JN (2000) A review of health-related work outcome measures and their uses, and recommended measures. Spine 25:3152

13. Amick BC, Gimeno D (2008) Measuring work outcomes with a focus on health-related work productivity loss. In: Wittink H, Carr D (eds) Pain management: evidence, outcomes, and quality of life: a sourcebook. Elsevier, Amsterdam, pp 329-343

14. Abma F, Amick B, Klink J, Bültmann U (2013) Prognostic factors for successful work functioning in the general working population. J Occup Rehabil 23:162-169

15. Deimling GT, Bowman KF, Sterns S, Wagner LJ, Kahana B (2006) Cancer-related health worries and psychological distress among older adult, long-term cancer survivors. Psycho-Oncol 15:306-320

16. Wagner LI, Cella D (2004) Fatigue and cancer: causes, prevalence and treatment approaches. Br J Cancer 91:822-828

17. Wefel JS, Lenzi R, Theriault RL, Davis RN, Meyers CA (2004) The cognitive sequelae of standard-dose adjuvant chemotherapy in women with breast carcinoma: results of a prospective, randomized, longitudinal trial. Cancer 100:2292-2299

18. Feurstein M, Hansen JA, Calvio LC, Johnson L, Ronquillo JG (2007) Work productivity in brain tumor survivors. J Occup Environ Med 49:803-811

19. Lavigne JE, Griggs JJ, Tu XM, Lerner DJ (2008) Hot flashes, fatigue, treatment exposures and work productivity in breast cancer survivors. J Cancer Surviv 2:296-302

20. Hansen JA, Feuerstein M, Calvio LC, Olsen CH (2008) Breast cancer survivors at work. J Occup Environ Med 50:777-784

21. Feuerstein M, Todd BL, Moskowitz MC, Bruns GL, Stoler MR, Nassif T, Yu X (2010) Work in cancer survivors: a model for practice and research. J Cancer Surviv 4:415-437

22. Morgan DL, Krueger RA (1998) The focus group kit. Sage Publications, Thousand Oaks

23. Sandelowski M (2000) Focus on research methods. Whatever happened to qualitative description? Res Nurs Health 23:334-340

24. Kuper A, Lingard L, Levinson W (2008) Critically appraising qualitative research. BMJ 337:a1035

25. Bower JE, Ganz PA, Desmond KA, Rowland JH, Meyerowitz BE, Belin TR (2000) Fatigue in breast cancer survivors: occurrence, correlates, and impact on quality of life. J Clin Oncol 18:743-753

26. Lindley C, Vasa S, Sawyer WT, Winer EP (1998) Quality of life and preferences for treatment following systemic adjuvant therapy for early-stage breast cancer. J Clin Oncol 16:1380-1387

27. Servaes P, Verhagen S, Bleijenberg G (2002) Determinants of chronic fatigue in disease-free breast cancer patients: a crosssectional study. Ann Oncol 13:589-598

28. Grunfeld EA, Cooper AF (2012) A longitudinal qualitative study of the experience of working following treatment for gynaecological cancer. Psycho-Oncol 21:82-89

29. NVAB (2009) Blauwdruk Kanker en Werk (Blueprint Cancer \& Work). Utrecht

30. Abma FI, Bültmann U, Varekamp I, van der Klink JJL (2013) Workers with health problems: three perspectives on functioning at work. Disabil Rehab 35:20-26

31. McKay G, Knott V, Delfabbro P (2013) Return to work and cancer: the Australian experience. J Occup Rehabil 23:93-105

32. de Boer AGEM, Verbeek JHAM, Spelten ER, Uitterhoeve ALJ, Ansink AC, de Reijke TM, Kammeijer M, Sprangers MAG, van Dijk FJH (2008) Work ability and return-to-work in cancer patients. Br J Cancer 98:1342-1347 